Journal of Education and Vocational Research

Vol. 1, No. 2, pp. 44-52, May 2011

\title{
An Investigative Study of Job Satisfaction in Bhakra Beas Management Board
}

\author{
Suresh Kumar \\ Department of Commerce, Govt. Degree College Bhoranj (Tarkwari), Hamirpur, (Himachal Pradesh) INDIA \\ suresh.commerce@gmail.com
}

\begin{abstract}
The present study deals with the empirical results regarding the study of job satisfaction in Bhakra Beas Management Board. The study is attempted to assess the job satisfaction and their means difference among various satisfaction levels. The satisfied and dissatisfied groups to job satisfaction mean difference is also attempted. The disruptive research method is found suitable for this purpose. Primary data has been assembled by employing questionnaire. A sample of 360 respondents was selected from all unit of organization. The content, construct and item to total correlation validity were established. Reliability of the instrument was justified through the calculation of cronbach's $(\alpha)$ alpha coefficient. The test-retest measure of reliability coefficient for job satisfaction scale was found acceptable. The finding appears to be reasonably valid in view of the deplorable socio- economic conditions of the employees and their factors influencing job satisfaction.
\end{abstract}

Keywords: Satisfaction, Bhakra Beas Management Board (BBMB), Variance, descriptive Survey

\section{Introduction}

Job satisfaction constitutes the inner contentment that a job holder gets by performing the job well. It is an amount of pleasure associated with a job. It influences the behaviour, attendance and length of service. Job satisfaction reflects the overall attitude of workers towards the work, co-workers, the organization, the culture, the environment and the social group at large. It can be viewed as the result of various attitudes that the worker holds towards his job, towards other related factors and towards life in general. The growth of an organization depends upon the efficiency of its employees. The efficiency of the workers depends not only on how they work, but also on optimal social and physical conditions, in which they work. If they are not satisfied with their job or working conditions, the organization will not be able to achieve its objectives.

Increasing job satisfaction is important for its humanitarian value and for its financial benefits in order for an organization to be successful. Therefore, they must continuously ensure the satisfaction of their employees. Job satisfaction constitutes the inner contentment that a job holder gets by performing the job well. It is an amount of pleasure associated with a job. It influences the behavior, attendance and length of service. Job satisfaction reflects the overall attitude of workers towards the work, co-workers, the organization, the culture, the environment and the social group at large. It can be viewed as the result of various attitudes that the worker holds towards his job, towards other related factors and towards life in general. The happiness or pleasure that an employee gets by using this knowledge and skill effectively, result in job satisfaction. It is the psychological satisfaction a person gets by using his strengths and talents effectively. Job satisfaction reflects the attitude which results from a balancing and summation of the many likes or dislikes and experiences in connection with a job. The mixture of feelings, attitudes and sentiments that contribute to a general feeling of satisfaction gives rise to job satisfaction.

Rationale behind the Study: The quality of an organization is to a large degree merely the summation of the quality of people it hires and keeps. Getting and keeping competent employees is critical to the success of every organization studies on job satisfaction seen to begin with the famous Hawthorne studies conduct by Elton mayo at the western electric company in the 1920. .Most of the studies conducted so for are in industrial setting and particularly in private sectors. Elton Mayo and his co-workers started very much in this direction during the course of their investigation however; they become convinced that factors of a social nature also affect job satisfaction. The human relation school was thus born which saw the function of the industrial psychologist as seeking to improve the happiness of the workers and through this to improve productivity. Going through the available literature in India and outside it has been observed that quite a substantial work 
have been done on the job satisfaction. But such work has to be researched in the light of emerging dimensions of job satisfaction. Hence researcher decided to undertake a study of job satisfaction in Bhakra Beas Management Board which is premier in contribution to the performance and effectiveness of organization as well to the employee's overall development.

For the propose of present investigation the study has been confined to Bhakra Beas Management Board which is a joint collaboration of undivided states of Punjab and Rajasthan known as Bhakra Nangal \& Beas project. The study has been conducted during 2008 to 2010. The objectives of the study are:

- To study the perceived levels of Job Satisfaction.

- To Compare and contrast the levels of job satisfaction and

- To determine the significant difference in satisfied and dissatisfied groups.

\section{Review of Literature}

The credit for bringing this term into account goes to the Hoppock (1985) who defined job satisfaction as any combination of psychological, physiological and environmental circumstances that cause a person truthfully to say,' I am satisfied with my job. Maslow (1954) in his study of the hierarchy of human needs provided the basic foundation for many subsequent studies on job satisfaction. Locke $(1969,1970)$ and Locke and Whiting (1974) provided comprehensive definition of job satisfaction as a pleasurable or positive emotional state resulting from the appraisal of one's job or job experience. Job satisfaction essentially means economy of efforts, getting rid of available tension, utilizing the energies of employees for better performance of work; instead of allow them to be dissipated needless. According to Bulm and Naylor (1968), job satisfaction is the result of various attitudes possessed by an employee. Gilmer (1966) defined as job satisfaction or dissatisfaction is the result of various attitudes the person holds towards the Job, towards related factors and toward life in general. Job satisfaction is a complex phenomenon as described by Rao (1970), having a multiple inter-correlated causal factors: personal, social, cultural and economic.

According to Kartzel (1964) job satisfaction is the verbal expression of an incumbent's evaluation of his job. Dhillon (1989) investigated the relationship between perceived occupational stress and job satisfaction among 176 male officers of police organization in Delhi. Choudhry (1989) studied on, "Occupational level and Job Satisfaction- a Comparative Study of Public and Private Sector Organization". The study was carried out with the two fold objectives to study and compare the extent of the job satisfaction among the employees of private and public sector and to compare the extent of job satisfaction within the hierarchical status. Hussain (2000) conducted a study on job satisfaction among private and public sector bank employees. The study revealed that public bank employees were in a better position in terms of job satisfaction than the private sector.

On the basis of literature following hypotheses are formulated:

$\mathbf{H}_{\mathbf{1}} \quad$ : Generally the employees found dissatisfied with their job

$\mathbf{H}_{2} \quad$ : There is insignificant mean difference among job satisfaction Levels.

$\mathbf{H}_{3} \quad$ : Satisfied and dissatisfied group have equal effect on job Satisfaction score.

\section{Methods}

Measures: For accomplishing the objectives of the present study both primary and secondary data of Bhakra Beas Management Board was utilized. Primary data has been collected by administrating the questionnaire. A structured questionnaire was developed by dividing the whole questionnaire in two main sections and sub sections. The questionnaire was mainly focused on the problems, (I) to collect the personal data of socio economic demographics and (ii) to gather the inventory of job satisfaction. Bearing the important dimensions of job satisfaction, a number of variables related to job satisfaction inventory were collected from a number of sources i.e. present and former employers of Bhakra Beas Management Board and other organizations. The expert opinion in this field of this particular research was also attempted. The item pool thus refined was presented to the 30 experienced employee's who were requested to add other statements that might be 
relevant to the subject to point out redundant statements to mark ambiguous and double barred "items" if any and to give suggestion for refining the items in the above pool. The suggestions were incorporated and 30 facets were selected and were included in the preliminary form. At a very early stage in the pilot study it becomes evident that certain items were either ambiguous, unclear or the respondents did not understand them properly. The discriminating potential and suggested changes by the respondents were also included in the final form. The flat and ambiguous statements were dropped. Since the statements were qualitative they were quantified on five point scale using likert type technique. The questionnaire was divided into two sections; Section-1 was of personal data sheet comprising 16 socio-economic variables and section- 2 of job satisfaction inventory (JSI). After the pilot survey a 21 facet job satisfaction inventory was employed with grouping of four job satisfaction dimensions as organizational factor dimension (6 facet), work-environment factor dimensions (6 factor) work itself factor dimension (4) and personal factor dimensions (5 factor) for items see appendices. Initially the permission of board administration was sought and four hundred questionnaires were distributed personally among respondents. The fully responded questionnaires were utilized for further processing. The instructions were written in the opening of various sections and sub sections of the questionnaire.

Procedures: The Content item and construct validity of job satisfaction facets were established. The construct validity of inventory was found very high which ranges from 0.82 to 0.84 . The construct validity supports the items to total correlation validity. Keeping in view the objectives and the nature of data required under study the questionnaire method for data collection and the help of Mathematical, Tabular, Graphical and the Statistical methods were used. Statistical analysis was performed through the SPSS -17.

Reliability Estimate of the Instrument: Reliability of the instrument was justified firstly through the calculation of cronbach's alpha $(\alpha)$ coefficient (cronbach's 1951 the observed coefficient value of job satisfaction scale 0.9110) has been observed above the Nunnally and Bernstein (1994) Criterion (0.70) hence could be classified as acceptable reliable instrument. The test-retest (one month interval between the two administration) measure of reliability coefficient for job satisfaction scale were found acceptable reliable $(>0.80)$.

Scoring Procedure Followed: The responses on the job satisfaction inventory were assigned on a five point likert scale containing categories of highly satisfied (5) moderating satisfied (4) neither satisfied nor dissatisfied (3) Dissatisfied (2) Highly dissatisfied (1) figures in parenthesis denoting their weightage. In this manner scores on job satisfaction inventory for low medium and higher level has been determined. The summated score may range between 21 to 105 .

Sample Design and Sample Size: For the present research work qualitative approach is undertaken by the researcher. The sampling gives liberty to the researcher to minimize the population and by the sincere effort of researcher can make the sample size real representative of the total population. The entire manpower of Bhakra Beas Management Board is the population under study. The selection of respondents were ultimately made on convenient cum judgment method of non-probability sampling and the sample selection is shown in Table No.1

Table 1: Sample Selection from Existing Population of BBMB

\begin{tabular}{lccc}
\hline Employees Categories & Sanctioned Strength & Existing Strength & Sample (5\%) \\
\hline A (officers) & 269 & 219 & $30^{*}$ \\
B (officers) & 409 & 290 & $30^{*}$ \\
C (Non-officers & 8183 & 6127 & 300 \\
D (Non-Officers) & 6175 & 4910 & Nil** $^{* *}$ \\
Grand Total & 15036 & 11546 & 360 \\
\hline
\end{tabular}

* Sample Selection based on 5\% from each category (subject to a minimum of 30 employees of each category).

** ' $D$ ' category employees were excluded from population on the basis of pilot survey and non response behavior of this category 


\section{Results and Discussion}

Assessment of Job Satisfaction Levels: An attempt is made to analyze overall Job Satisfaction of employees of the Bhakra Beas Management Board. The scores obtained, for this purpose from all units; on all aspects are 21 in numbers that is been discussed in the research methodology. These scores are pooled together to compute the overall index of employees Job Satisfaction. The formulated data has been discussed in the Table 2 .

Table 2: Index of job satisfaction levels in BBMB

\begin{tabular}{cccc}
\hline Scores & Levels of Job Satisfaction & No. of Employees (N) & Percentages (\%) \\
\hline $21-62$ & Low & 21 & 5.80 \\
$63-83$ & Medium & 185 & 51.40 \\
$84-105$ & High & 154 & 42.80 \\
& Total & 360 & 100 \\
\hline
\end{tabular}

Table 2 depicts that the scores of the Job Satisfaction are skewed on the positive side, indicating thereby that the employees of said organization possess favorable attitude towards the Job. A majority (51.40) of the respondents shows a medium level of Job Satisfaction. A moderate percentage (42.8) is found highly satisfied with their Jobs. Only 5.80 percent of the respondents perceive the lower level of Job Satisfaction. The above finding reported in table and graph 1 and its interpretation does not confirm the $\mathrm{Ho}_{1}$ in this regard. The finding of the present study appears to be reasonably valid in view of the deplorable socio-economic conditions of the employees and their factors influencing Job Satisfaction.

\section{Graph 1: Job Satisfaction Index}

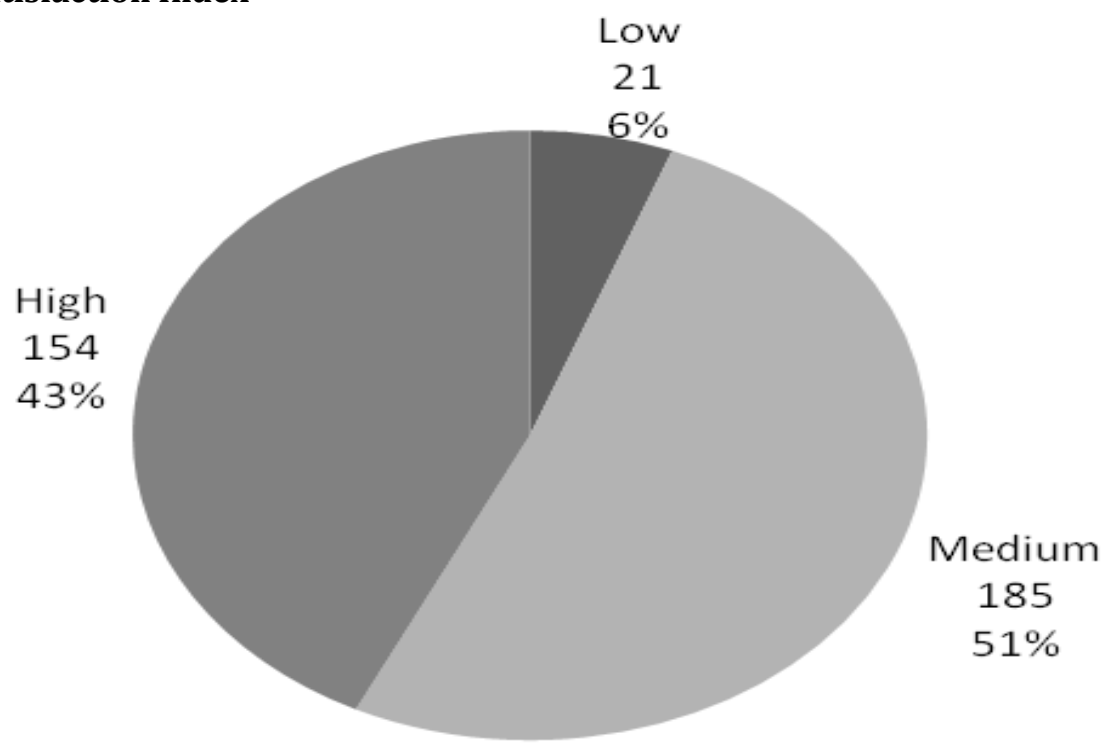

It would be worthwhile to make a comparative analysis of the results of this study with other research evidences on the subjects in the Indian context. Table.3 summarizes the relevant information from the major studies on Job Satisfaction. In India the statistics contained in Table-3 reveals that the Individual studies of Dubey et al (1989) bank Officers in India, Srivastava and Pratap (1984), HAL Kanpur, Johri of Delhi represent different nature of work and its implications for the findings to the present study. 
Table 3: Job Satisfaction of Workers in View of the Major Studies in India (In Percentages)

\begin{tabular}{|c|c|c|c|c|c|c|c|}
\hline \multirow[t]{2}{*}{$\mathbf{S} / \mathbf{N}$} & \multirow{2}{*}{$\begin{array}{c}\text { Researcher } \\
\text { (Year of Study) }\end{array}$} & \multirow{2}{*}{\multicolumn{2}{|c|}{$\begin{array}{l}\text { Scope and Size } \\
\text { (Sample) }\end{array}$}} & \multicolumn{4}{|c|}{ Levels of Job Satisfaction } \\
\hline & & & & $\begin{array}{c}\text { Highly } \\
\text { Satisfied }\end{array}$ & $\begin{array}{l}\text { Moderately } \\
\text { Satisfied }\end{array}$ & $\begin{array}{l}\text { Moderately } \\
\text { Dissatisfied }\end{array}$ & $\begin{array}{c}\text { Highly } \\
\text { Dissatisfied }\end{array}$ \\
\hline 1. & $\begin{array}{l}\text { Pestonjee } \\
\text { (1974) }\end{array}$ & $\begin{array}{c}\text { Industrial Workers, } \\
\text { Ahmedabad }\end{array}$ & $(\mathrm{N}=\mathrm{N} . \mathrm{A})$. & 21 & 42 & 37 & - \\
\hline 2. & $\begin{array}{l}\text { Ganguli } \\
\text { (1954) }\end{array}$ & $\begin{array}{c}\text { Engineering } \\
\text { workers Calcutta }\end{array}$ & $(\mathrm{N}=284)$ & 3 & 63 & 29 & 5 \\
\hline 3. & $\begin{array}{l}\text { Srivastava \& } \\
\text { Singh (1974) }\end{array}$ & $\begin{array}{c}\text { Industrial Workers, } \\
\text { Chandigarh }\end{array}$ & $(\mathrm{N}=173)$ & 23 & 36 & 41 & - \\
\hline 4. & $\begin{array}{l}\text { Dubey et.al. } \\
\text { (1989) }\end{array}$ & Bank Officers, India & $(\mathrm{N}=88)$ & 44 & 42 & - & 14 \\
\hline 5. & $\begin{array}{l}\text { Srivastava \& } \\
\text { Singh (1974) }\end{array}$ & $\begin{array}{c}\text { Industrial Workers, } \\
\text { Chandigarh }\end{array}$ & $(\mathrm{N}=135)$ & 3 & 51 & 39 & 7 \\
\hline 6. & $\begin{array}{l}\text { Mukherji } \\
\text { (1985) }\end{array}$ & $\begin{array}{l}\text { Jute Workers, } \\
\text { Bengal }\end{array}$ & $(\mathrm{N}=310)$ & 5 & 10 & $66^{* *}$ & 19 \\
\hline 7. & $\begin{array}{c}\text { Srivastava \& } \\
\text { Pratap (1984) }\end{array}$ & $\begin{array}{l}\text { Public and Private } \\
\text { Sector* textile } \\
\text { Workers Kanpur }\end{array}$ & $(\mathrm{N}=856)$ & 22 & 52 & 26 & - \\
\hline 8. & Johri (1969) & $\begin{array}{l}\text { Building Workers, } \\
\text { Delhi }\end{array}$ & $(\mathrm{N}=100)$ & 35 & - & 61 & 4 \\
\hline 9. & $\begin{array}{l}\text { Srivastava et } \\
\text { al (1995) }\end{array}$ & $\begin{array}{c}\text { Industrial workers, } \\
\text { H.A.L., Kanpur }\end{array}$ & $(\mathrm{N}=100)$ & 70 & - & 20 & 10 \\
\hline
\end{tabular}

${ }^{*}$ Scores of Public and Private Sector Workers Pooled Together.

** Scores of "Moderately Dissatisfied are neither Satisfied nor dissatisfied percentages".

While the most of the findings of research studies are contrary to the present study, including Pestonjee (1974) of Ahmedabad, Ganguli (1954), Calcutta , Srivastava and Singh (1974) of Chandigarh and Mukherjee (1985) of Kanpur. But in these studies, it is found that workers perceive either moderate or medium level of Job Satisfaction. The general consideration is in the middle and a negligible percentage is concentrated on the extreme ends of the Job Satisfaction/dissatisfaction continuum (Singh and Srivastava, 1983).

Analysis of Job Satisfaction Levels: The employees of an organization were divided into three groups: low, medium and high level on the basis of methodology. Those who scored less than 63 (mean score) were classified into low level Job Satisfaction group. The respondents who scored equal to 63 or more than 63 but below 84 have been kept into medium level Job Satisfaction group. Further, the respondents who scored equal to 84 or more than 84 have been kept into a higher level Job Satisfaction group.

Table 4: An Analysis of Job Satisfaction Levels

\begin{tabular}{cccc}
\hline Job Satisfaction Levels & $\mathbf{N}$ & Mean $(\bar{X})$ & Std. Deviation $(\boldsymbol{\sigma})$ \\
\hline Low & 21 & 58.05 & 3.75 \\
Medium & 185 & 76.32 & 4.99 \\
High & 154 & 91.98 & 6.31 \\
Overall & 360 & 81.96 & 11.11 \\
\hline
\end{tabular}

Source: Data collected through questionnaire.

Graph 2: Job Satisfaction Levels Means

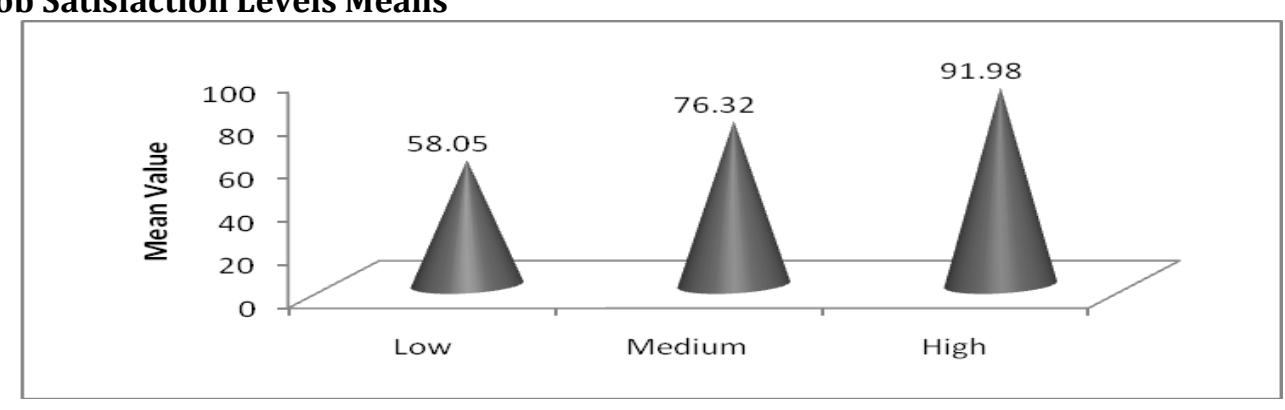


Table 5: Variance analysis of job satisfaction levels

\begin{tabular}{lcccc}
\hline Groups & Sum of Squares & d.f. & Mean Square & F. Value \\
\hline Between Groups & 33346.85 & 2 & 16673.43 & $542.48^{*}$ \\
Within Groups & 10972.43 & 357 & 30.74 & \\
Total & 44319.28 & 359 & & \\
\hline
\end{tabular}

** Significant at 0.01 level of significance.

The mean Job Satisfaction score and SD's of the three subject groups have been presented in the table 5. The mean score of the three groups (Low, Medium or High) is 58.05, 76.32 and 91.98 respectively. The low level satisfaction score is the only group who obtained less than the neutral point (63). But, the medium and high Job Satisfaction level groups obtained more than neutral point. It indicates that the two employee groups are satisfied with their Job. One way ANOVA test has been applied to find out, the significant difference between the three levels of Job Satisfaction. The result of analysis presented in the table shows that the ' $F$ ' ratio was significant at 0.01 levels, indicating that there is significant mean difference of high level Job Satisfaction within the employee groups. Thus, the null hypotheses $\left(\mathrm{Ho}_{2}\right)$ have not been confirmed in this regard that different Job Satisfaction levels have no significant difference towards means on Job Satisfaction. The present study in the line by Fisher and Hanna (1931), Mehdi and Sinha (1971) and Anand (1977) reported that the job satisfaction and different scores obtained by the respondents had significant difference.

A Comparative Analysis of Satisfied and Dissatisfied Groups of Employees: The Job Satisfaction Inventory (JSI) by taking all variables into consideration viz. (a) Highly satisfied (b) Partially Satisfied (c) Dissatisfied and (d) Highly dissatisfied have been included to elicit a direct responses from the respondents about their Job satisfaction/dissatisfaction. On the basis of their responses to the above item, the 360 employees of Bhakra Beas Management Board who have participated in the study were classified into four groups- (1) highly satisfied, (2) partially satisfied, (3) Dissatisfied and (4) highly dissatisfied with the item. The responses of highly satisfied and partially satisfied employees have been merged into one group i.e. 'satisfied', 'Dissatisfied' and 'highly dissatisfied' responses, were combined into another (dis-satisfied) group. The mean scores on overall job satisfaction of the highly satisfied, partially satisfied, dissatisfied and highly dissatisfied groups are $88.11,79.76,70.83$ and 84.25 respectively.

Table 6: Respondents Distribution on Job Satisfaction Ratings

\begin{tabular}{clcccc}
\hline S. No. & \multicolumn{1}{c}{ Responses } & N & Percentage & Mean $(\bar{X})$ & SDs (б) \\
\hline 1. & Highly Satisfied & 148 & 41.11 & 88.11 & 8.46 \\
2. & Partially Satisfied & 156 & 43.33 & 79.76 & 9.06 \\
3. & Dissatisfied & 52 & 14.44 & 70.83 & 10.63 \\
4. & Highly Dissatisfied & 4 & 1.11 & 84.25 & 20.98 \\
& Total & 360 & 100 & & 11.11 \\
\hline
\end{tabular}

Source: Data collected through questionnaire.

\section{Graph 3: Job Satisfaction Rating Distribution}

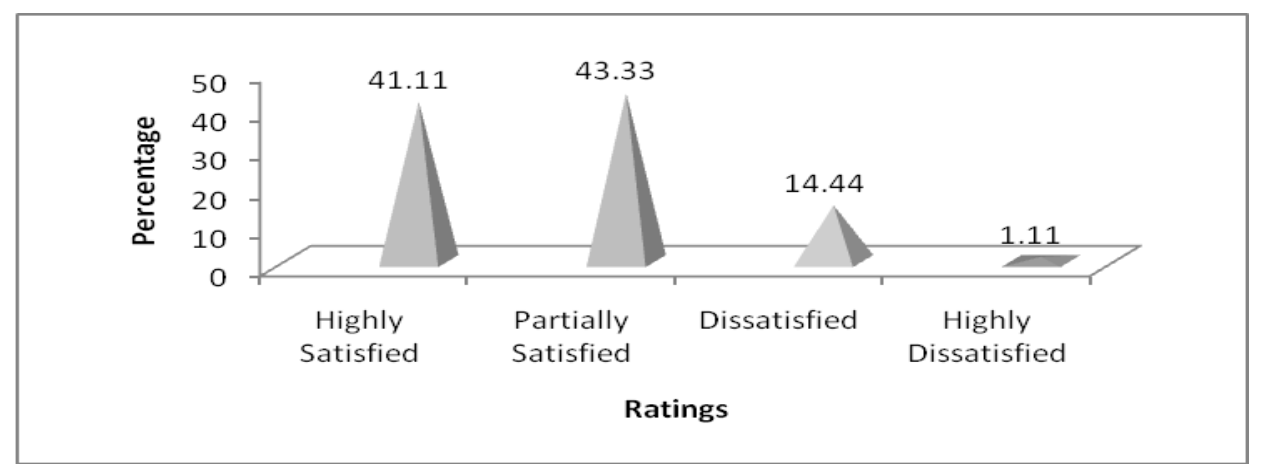


Table 7: Comparison between Satisfied and Dissatisfied Groups on Job Satisfaction

\begin{tabular}{ccccc}
\hline Groups & $\mathbf{N}$ & Mean $(\bar{X})$ & SD $(\boldsymbol{\sigma})$ & 't' value \\
\hline Satisfied & 304 & 83.83 & 9.90 & $8.096^{*}$ \\
Dissatisfied & 56 & 71.79 & 11.87 & \\
\hline
\end{tabular}

*Significant at .01 level of significance.

The mean scores of the satisfied and dissatisfied group as measured by the Job Satisfaction Inventory are 83.83 and 71.79 respectively. To test whether the two mean scores were significantly different, ' $t$ ' test was employed.

\section{Graph 4: Employee Distribution in Satisfied and Dissatisfied Groups}

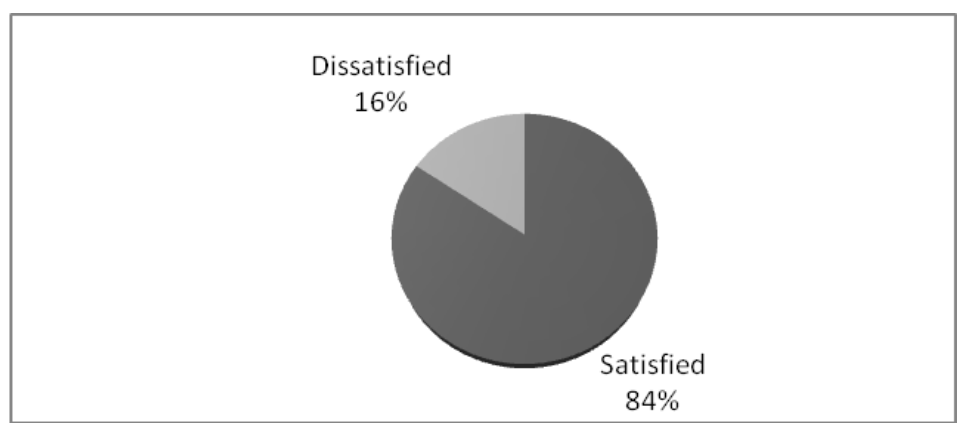

The result of the ' $t$ ' test presented in the table 7. The mean score of those who were satisfied (83.83) greater than the mean scores of dis-satisfied group (71.79). The calculated ' $t$ ' value (8.096) shows significant results at 0.01 level. The result of the above analysis supports the alternate hypothesis that satisfied and dissatisfied group of employees have significant difference on the Job Satisfaction scores observed. The proposed null hypothesis $\left(\mathrm{Ho}_{3}\right)$ may be rejected in support of present finding.

\section{Limitations of the Study}

To complete the present research work no stone has been left unturned in view to make it best possible work. Non-probability method of sampling, stringency of time, resources, and the incomplete and non-responses of certain items may lose the tools authenticity. The concept of job satisfaction is not entirely specific even though efforts have been made to use it in the present study to meet our purpose. The rating method of job satisfaction rating is not a full proof method. Despite of these limitations all precautions have been made in order to make its impact negligible on the research results and findings.

\section{Conclusion and Suggestions}

As far as the Job Satisfaction levels are concerned, the majority of the respondents were belonging to the medium level of satisfaction (51.40 percent) followed by high level (42.80 percent). Whereas, only 5.80 percent respondents were found with low level of satisfaction. The low level mean satisfaction score found (58.05) lower than the standard mean score (63). Further, the difference between mean scores of Job Satisfaction levels was found significant. Thus, the higher level Job Satisfaction mean widely differed. Single Global approach of measuring Job Satisfaction supports summated approach by revealing partially satisfied employees as dominant among four groups (highly satisfied, partially satisfied, Dissatisfied, Highly dissatisfied). Furthermore, the four groups were classified in satisfied and dissatisfied groups to test the mean difference on overall job satisfaction (summated score). The satisfied and dissatisfied group means difference was found significant. It is clear that satisfied group mean score is significantly ranged. Despite being the majority respondents have expressed medium and higher job satisfaction levels, the mean difference of the three levels found significantly differed. Therefore, there is a need to increase the mean scores of medium and lower level satisfied employees by providing promotions and advancement measures and other dry promotions practices. Researchers debated with regard to satisfied and dissatisfied groups. The 
observed mean score found statistically significant. It is therefore, required to convert the dissatisfied employees into satisfied employees by encouraging employees to participate in management and recognizing their work.

\section{Identification of Area for the Further Research}

A number of studies including the present one have been conducted on job satisfaction in the public and private sector. The present study has been conducted for the realization of certain objectives. Though, every attempt has been made to make the study comprehensive besides, certain areas have still remained unexplored. Job satisfaction is a culture specific exercise. Its form and contrast very with prevailing socioeconomic, cultural and technological milieu of a country. There are still certain areas left on which further research should be carry out

- No discovery is final verdict in a particular area of research

- A replication of the same study can be carried out having a wider research area

- Similar group of respondents to be used for such validation

- A comparative study to be carried out for private and public sector undertaking

- Further, the researches have to apply a standard tool for data collection

- An in-depth investigation on satisfied and dissatisfied employees may be an immense practical utility to the Human resource practitioner and it can also have same theoretical value as it could throw light on Herzberg's two factor theory

\section{References}

Anand, S. P. (1977). School Teachers: Job Satisfaction Vs extraversion and Uroticism. Indian Educational Review, 12(2): 68 - 78.

Bulm, M. and Naylor, J. (1996). Industrial Psychology: its theoretical and social foundation, Herber and Row: New York.

Choudhry, S. (1989). Occupational Level and Job Satisfaction. Indian Journal of Applied Psychology, 26(2): 1-5.

Dhillon, P. K. (1989). Relationship between Organizational Stress and Job Satisfaction. Indian Journal of Current Psychological Research, 4(1): 42-47.

Dubey, B. L., Uppal, K. K., and Verma, S. K. (1989). Further validation of a job satisfaction scale. Indian Psychological Review, 34.

Fisher V. and Hanna J. (1931). The Dissatisfied Worker. NY: Macmillan.

Ganguli, H. C. (1954). An inquiry into incentives for workers in an engineering industry. Indian Journal of Social Work, 15: 34-37.

Gilmer, V. V. (1966). Industrial Psychology. McGraw Hill, Koyakusha Co. Ltd., Tokyo, 254-263.

Hoppock, R. (1935). Job Satisfaction, New York: Horper.

Kartzel, R. A., (1964). Personal Values, Job Satisfaction and Job Behavior. Houghton Mifflin Company, 341-363, Boston.

Locke, E. A. (1969). What is Job Satisfaction? Organizational Behavior and Human Performance 4: 309-336.

Locke, E. A., and Whiting, R. J. (1974). Source of Satisfaction and Dissatisfaction among Solid Waste Management Employees. Journal of Applied Psychology, 59(2): 145-156.

Locke, E. A. (1970). Job Satisfaction and Job Performance: A Theoretical Analysis. Organizational Behavior and Human Performance, 5: 484-500.

Maslow, A. H. (1954). Motivation and Personality. N. Y., Harper and Row.

Maslow, A. H., (1943). A Theory of Human Motivation. Psychological Review, 50: 370-396.

Mayo, E. (1945). The Human Problems of an Industrial Civilization. Boston: Harvard Business School.

Hussain, M. (2000). Job satisfaction of Commercial bank employees in Bank employees in Bangladesh: A Comparative study of private and Public sectors. Indian Journal of Industrial Relations, 35(4) 397361.

Mukherji, N. N. (1985). A Factor -Analysis story of Job Satisfaction. Indian Journal of Industrial Relations, 5: 429-439. 
Nunnally, J. C. \& Bernstein, I. H., (1994). Psychometric Theory (3'rd Ed.). New York: McGraw-Hill.

PestonJee, D. M. (1974). Organization Structures and Job attitudes. The Minerva Associates, 20.

PestonJee, D. M. and Singh M. (1990). Job Involvement, Sense of participation and Job satisfaction -A study of Banking Industry. Indian Journal of Industrial Relation, 26(2): 159-165.

Singh, A. P. and Srivastva, S. (1983). Effect of need for achievement on job performance-job satisfaction relationship. Indian Journal of Industrial Relations, 18(3): 437-442.

Srivastava, S. K. and Singh, M. M. (1974). An inquiry into the relationship between Job Satisfaction and Job anxiety. Journal of Indian Academy of Applied Psychology, 9(2): 39-44.

Srivastava, S. K., Umesh, H. and Bajpai, N. (1995). Job Satisfaction in Public Sector. Indian Management, 44(5): 62-65.

Srivastva, S. K. (1987). Study of Relationship between Job Satisfaction and Organizational Climate. Indian Journal of Applied Psychology, 5(5): 18-25.

Srivastva, S. K. and Pratap, S. (1984). Perception of Job Satisfaction and Organizational Climate. Perspectives of Psychological Research, 7: 41-43. 